\title{
A New Method for the Determination of Three-Dimensional Deformation Anisotropy in Rock Specimens
}

GEOLOGICAL. SURVEY BULLETIN 1258 -E 


\section{A New Method for the Determination of Three-Dimensional Deformation Anisotropy in Rock Specimens}

By RICHARD A. FARROW

CONTRIBUTIONS TO ENGINEERING GEOLOGY

GE OLOGICAL SURVEY B ULLETIN $1258-$ E

A new laboratory technique for measuring orthotropic deformation anisotropy in single rock specimens and comparison of results with structural features in the source rock mass 


\section{UNITED STATES DEPARTMENT OF THE INTERIOR}

ROGERS C. B. MORTON, Secretary

\section{GEOLOGICAL SURVEY}

V. E. McKelvey, Director

Library of Congress catalog-card No. 72-600297 


\section{CONTENTS}

Abstract
Introduction
Ellipsoid of deformation
Test procedure and data reduction
Features of the granite and results of the test
Conclusions
References cited

\section{ILLUSTRATIONS}

Figure 1. Diagram showing dimensions of the specimen tested for this study.....

2. Equal-area lower hemisphere projection of successive changes of position of the principal axes of the strain ellipsoid for the first loading cycle.

Page

3. Equal-area lower hemisphere projection of successive changes of position of the principal axes of the strain ellipsoid for the second and third loading cycle.

4. Graphs showing microstrain per pound per square inch as a function of hydrostatic pressure.

5. Equal-area lower hemisphere projection of succcessive positions of the principal axes of the strain ellipsoid for the first loading cycle

6. Equal-area lower hemisphere projection of successive positions of the principal axes of the strain ellipsoid for the second and third loading cycles.

7. Graphs showing net principal strain magnitudes as a function of hydrostatic pressure. 


$$
\text { . }
$$




\title{
A NEW METHOD FOR THE DETERMINATION OF THREE-DIMENSIONAL DEFORMATION ANISOTROPY IN ROCK SPECIMENS
}

\author{
By Richard A. Farrow
}

ABSTRACI

A new laboratory technique for determination of anisotropic deformation in rock involves the application of hydrostatic stress to a single instrumented prism of rock. Measured strains are used to calculate a deformation ellipsoid. Determinations on Mount Airy "granite" agree well with published data. Directions of anisotropy in the test sample and structural features within the source rock mass appear to be related.

\section{INTRODUCTION}

Calculations of in situ stresses in rocks are made using measurements of length changes of linear elements that are taken when a mass of rock containing the linear elements is freed from the surrounding rock. Whether the linear element is quartz d-spacing (Friedman, 1967), borehole diameter (Merrill and Peterson, 1961), or a strain gage, bonded either to the rock itself (Leeman, 1964 ) or to an intermediate carrier (Nichols and others, 1968), the deformation characteristics of the rock must be determined in order to calculate stress in the rock.

Simplifying assumptions, such as that of linear elastic isotropy of the host rock, may yield stress determinations that are seriously in error (Becker and Hooker, 1967). Strains measured on the rock surface (or in the borehole) theoretically can be restored, under properly chosen triaxial stress conditions in the laboratory, to their original measure. A more practical approach was described by Becker (1968), who developed equations defining the relationships among stress, strain, and deformation in a thick-walled cylinder of rock subjected to triaxial loading. Among the limitations to his approach, as he pointed out, is the necessity for a geometric alinement between the cylinder and a plane of elastic symmetry. To obtain this required geometric alinement of the 
borehole, the elastic symmetry must be determined by laboratory testing (Panek, 1966).

In April 1969 the U.S. Geological Survey began a stress-field investigation at the quarry of the North Carolina Granite Corp. at Mount Airy, N.C. Fieldwork was done in cooperation with U.S. Bureau of Mines personnel who had previously worked in the area (Hooker and Johnson, 1969). Studies of long-term stresschange measurements and stress-relief overcoring are continuing. The present report concerns a new deformation test performed in the laboratory on a sample taken at the time of overcoring.

\section{ELLIPSOID OF DEFORMATION}

To simplify sampling and testing programs and to define the symmetry-of-deformation properties of rocks, a procedure was devised to measure anisotropic deformation under hydrostatic compression. The test is based on the assumption that when subjected to hydrostatic stress a circle of anisotropic material will deform into an ellipse and a sphere will deform into an ellipsoid. Anisotropy of this type is characterized by three mutually perpendicular axes. Along each of these axes the stiffness, or compliance, coefficients have different values. Materials possessing directional elastic properties with this particular symmetry are called orthotropic. Douglass and Voight (1969) have described an ellipsoid of Young's modulus for some North American granites which indicates that the assumption of orthotropic behavior may be justified for most granitic rocks.

One method of portraying the ellipsoid of strain (Timoshenko and Goodier, 1951, p. 224) is to define it as the locus of tips of all radial vectors, $r$, whose magnitude is given by $R=k / \sqrt{|\epsilon|}$, where $k$ is a constant and $\varepsilon$ is the normal strain in the direction of $r$. The ends of these vectors will all lie on the surface described by

$$
\pm k^{2}=\varepsilon_{x} x^{2}+\varepsilon_{y} y^{2}+\varepsilon_{z} z^{2}+\gamma_{y z} y z+\gamma_{x z} x z+\gamma_{x y} x y,
$$

where $x, y$, and $z$ form a right-handed Cartesian coordinate system, and $\gamma_{x y}$ is the shear strain in the $x y$ plane.

If $k=1$, and all strains are positive but not equal, the surface is an ellipsoid. If the principal axes of the ellipsoid are rotated to aline with the $x, y$, and $z$ axes, the equation simplifies to

$$
\pm k^{2}=\varepsilon_{x} x^{2}+\varepsilon_{y} y^{2}+\varepsilon_{z} z^{2} .
$$

These three strains, the principal strains, are designated $\varepsilon_{1}, \varepsilon_{2}$, and $\varepsilon_{3}$ for the maximum, intermediate, and minimum principal strains respectively. Throughout this report compressive strains are reckoned positive. 


\section{TEST PROGEDURE AND DATA REDUCTION}

An oriented specimen of Mount Airy "granite" of Stuckey and Conrad (1958) was deformed under hydrostatic pressure in a triaxial cell. The dimensions of the sample are shown in figure 1.

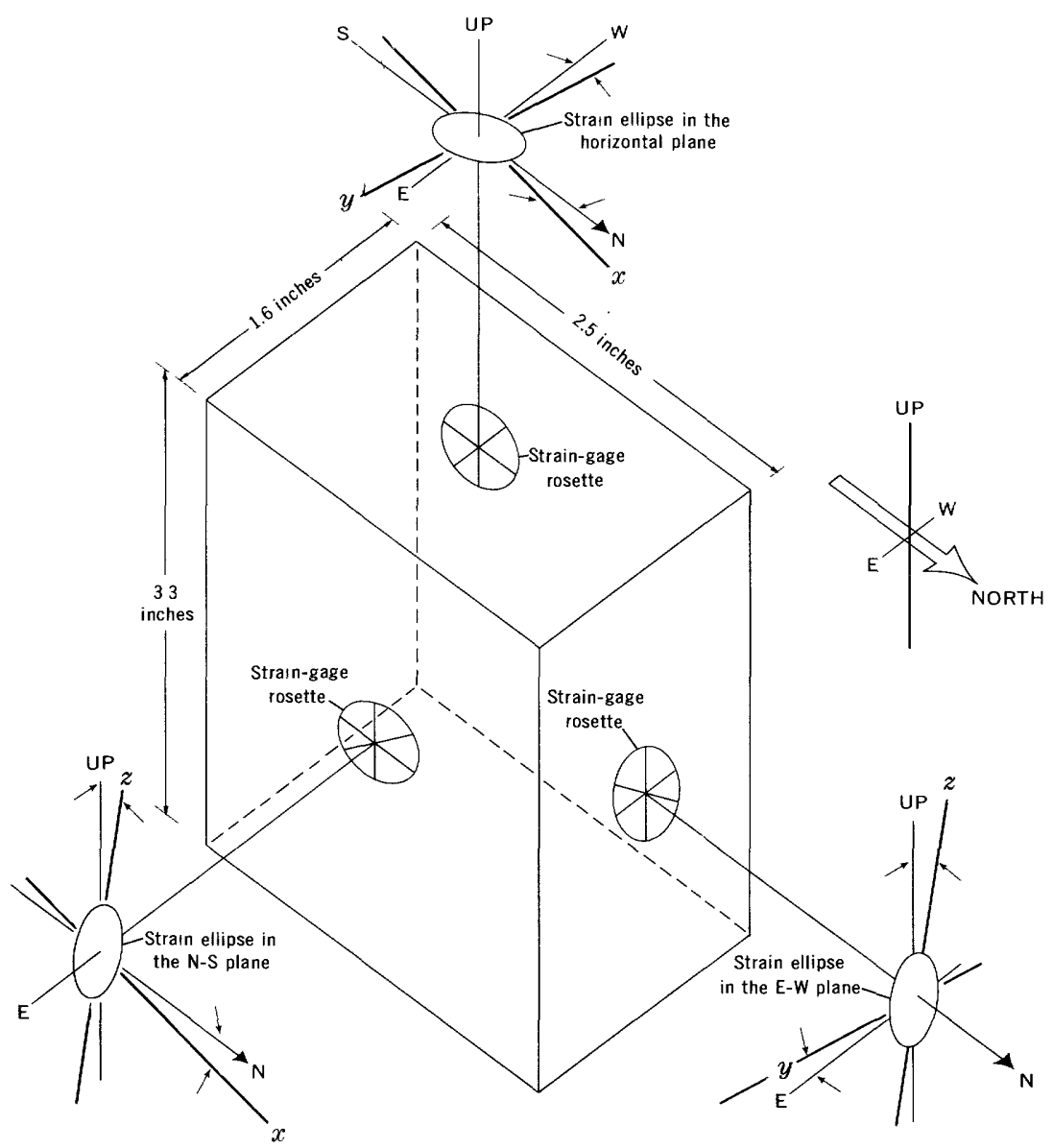

Figure 1. - Dimensions of the specimen tested for this study. Under hydrostatic stress, strain-gage rosettes on the three orthogonal faces measured unequal strains. These data were resolved into three ellipses and then were combined mathematically to form an ellipsoid of strain which rotated and changed shape under changing applied pressure.

Strain measurements were made in three orthogonal planes by three-component rectangular strain-gage rosettes bonded with epoxy to the surface of the specimen. The sample was coated with a clear semirigid epoxy compound to protect the electrical connections and to prevent entry of hydraulic fluid. Pressure was 
applied with a manual pump in increments as shown in figures 2-7 and was held while strain readings were recorded from a digital strain indicator. The whole procedure was carried out as rapidly as possible to minimize any effects of creep.

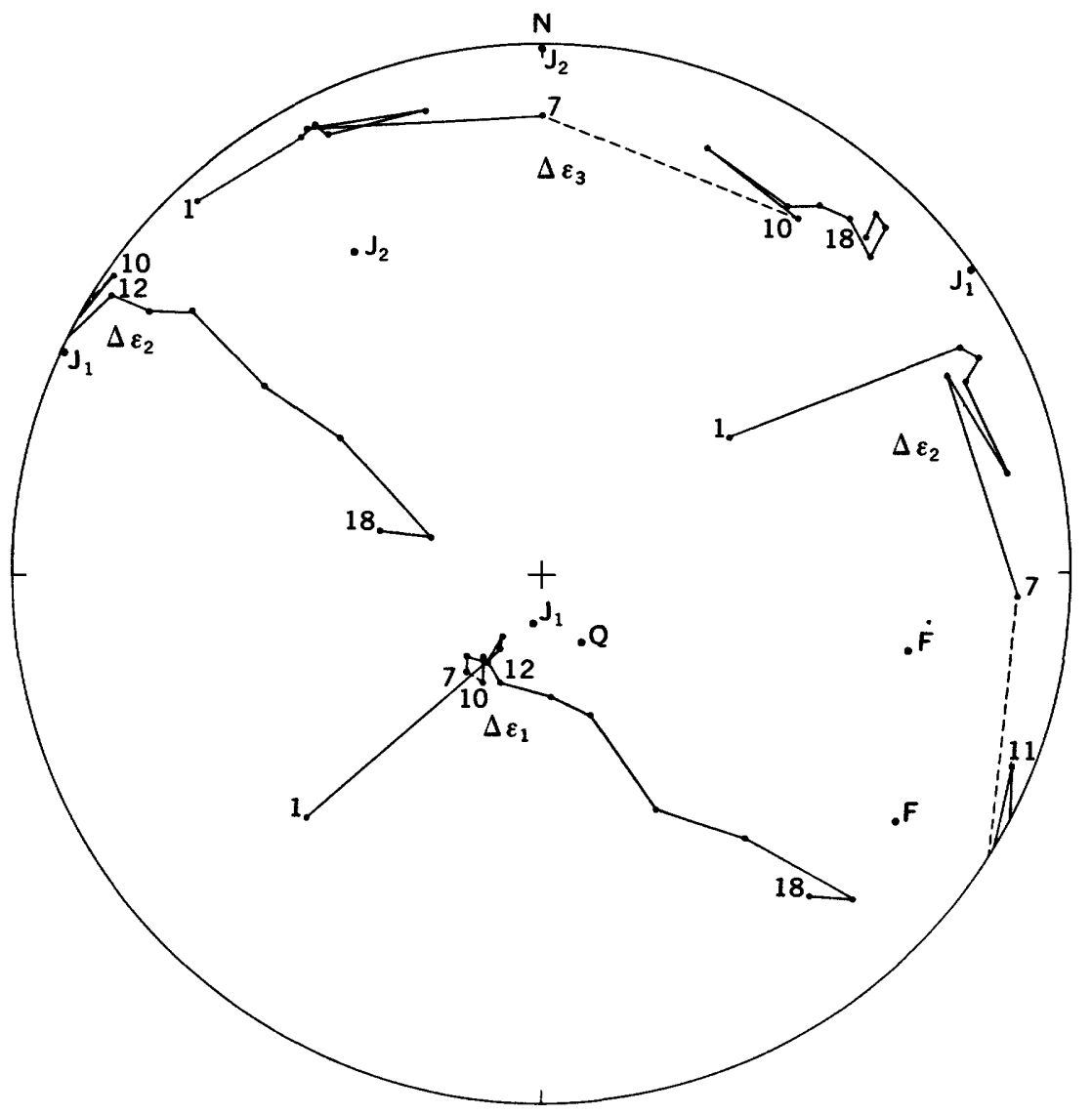

Figure 2. - Equal-area lower hemisphere projection of successive changes of position of the principal axes of the strain ellipsoid for the first loading cycle (loading-step numbers 1-18). $\Delta \varepsilon_{1}, \Delta \varepsilon_{2}$, and $\Delta \varepsilon_{3}$ are maximum, intermediate, and minimum compressive-strain changes. Also shown are poles of foliation (F), quarry floor (Q), three sets of prominent joints $\left(J_{1}\right)$, and two sets of moderate joints $\left(J_{2}\right)$.

For each pressure increment, and for the cumulative pressure changes, ellipsoids of strain change and total strain were defined using algorithms similar to those given by Obert and Duvall (1967). The method consists of finding the orientation of subsidiary principal strain axes and the magnitude of shear strain, $\gamma$, for each of three orthogonal planes. For each plane, two measure- 
ments of normal strain were averaged from gages on adjacent faces. This average was used for normal strain, $\varepsilon$, in the computations which lead to the three principal strain-magnitudes solutions, $\varepsilon_{1}, \varepsilon_{2}$, and $\varepsilon_{3}$, which, together with their direction cosines, define the deformation ellipsoid.

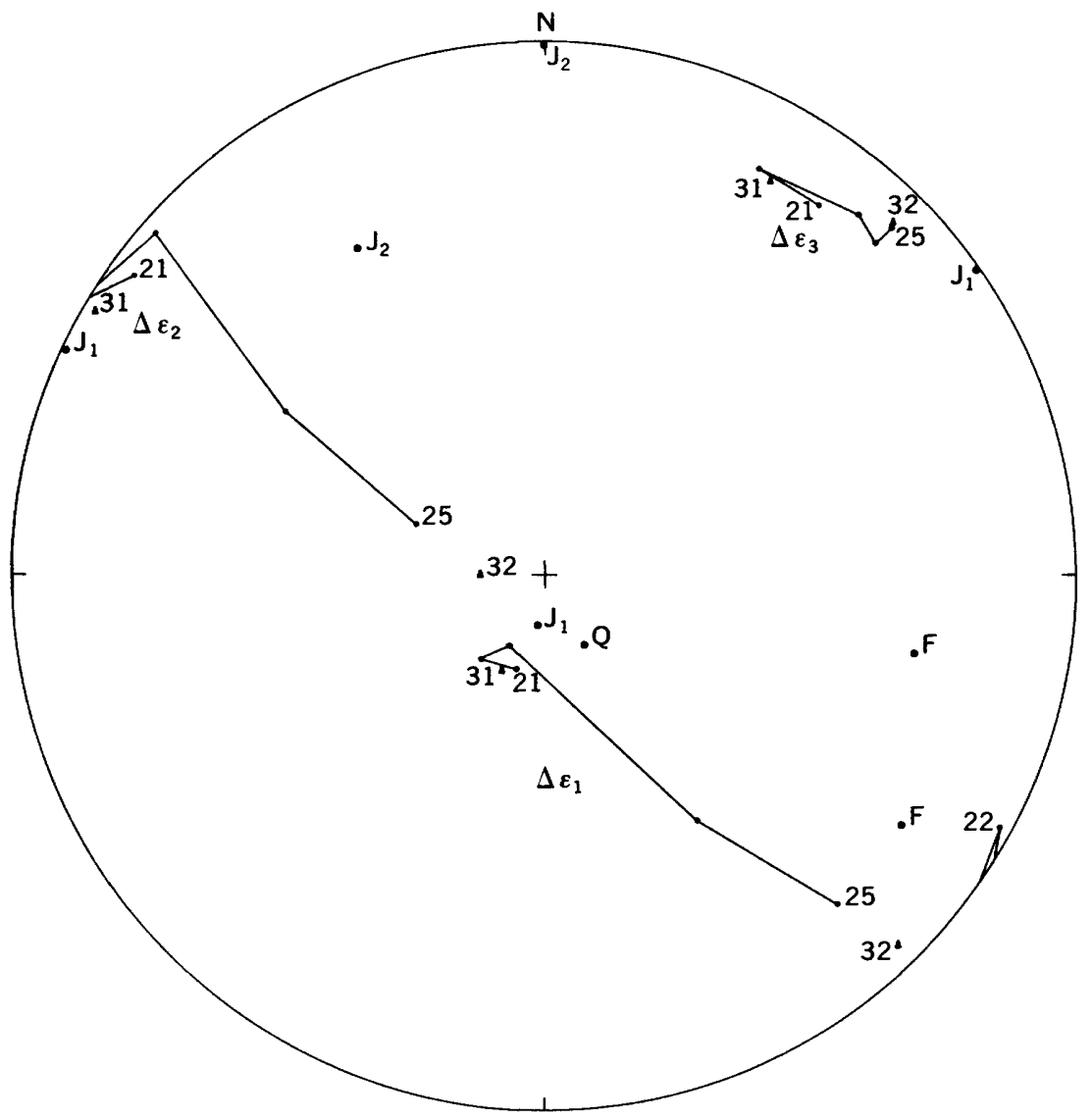

FIGURE 3. - Equal-area lower hemisphere projection of successive changes of position of the principal axes of the strain ellipsoid for second (loadingstep numbers 21-25; dots) and third (loading-step numbers 31 and 32 ; triangles) loading cycles. $\Delta \varepsilon_{1}, \Delta \varepsilon_{2}$, and $\Delta \varepsilon_{3}$ are maximum, intermediate, and minimum compressive strain changes. Also shown are poles of foliation (F), quarry floor (Q), three sets of prominent joints $\left(J_{1}\right)$, and two sets of moderate joints $\left(\mathrm{J}_{2}\right)$.

The orientation and magnitude of the principal axes of the strain ellipsoid can be shown graphically by several techniques. A variation of the methods described by Ramsay $(1967$, p. 134) is used here. Two diagrams define the changing strain tensor during 
deformation: (1) a lower hemisphere equal-area diagram onto which the axes of the ellipsoid are projected and which specifies the attitude of the strain ellipsoid at any given hydrostatic pressure, and (2) a diagram on which the principal strain magnitudes are plotted as a function of hydrostatic stress.

The simplifying assumption of elastic theory, that the deformation ellipsoid exhibits a constant and linear change at all stress levels, was not applicable to the Mount Airy "granite." In strainrelief overcoring, which has been performed at the Mount Airy quarry, the main interest is the behavior of the deformation ellipsoid for stress changes from 0 to the maximum relieved stress. For long-term monitoring of stress changes, the main interest is the behavior of the deformation ellipsoid at various confining stresses for incremental stress changes.

\section{FEATURES OF THE “GRANITE” AND RESULTS OF THE TEST}

The petrology of the Mount Airy "granite" has been discussed in detail by Dietrich (1961). He described the rock as a leucogranodiorite consisting of "approximately 55 percent oligoclase, 20 percent quartz, 20 percent microcline, and 5 percent other constituents, chiefly biotite, epidote, and muscovite. $* * *$ as exposed at the quarry, [it] is a foliated to nonfoliated holocrystalline, hypidiomorphic, medium-grained phanerite $* * *$. It has the overall appearance of being light gray with rather evenly disseminated black spots and (or) black streaks."

An unpublished geologic sketch map of the quarry made by F. T. Lee in 1970 shows the axial trace of an anticline which trends $\mathrm{N}$. $70^{\circ} \mathrm{E}$. and which is defined by sheeting joints parallel to the slope of the quarry floor. The specimen tested for this report shows neither foliation nor megascopic fractures. A detailed analysis of microfractures, similar to that made by Norman (1967) in granitic rocks near Atlanta, Ga., has not yet been made by the present author. Such microfractures could partly account for the measured deformation anisotropy of the rock (Norman, 1967).

Tests on the oriented specimen of Mount Airy "granite" demonstrated the dependence of both the orientation and the magnitude of the principal deformation axes upon the amount of stress. The orientation of the changes of the principal deformation axes relative to north, east, and vertical for incremental hydrostatic stress changes is shown in the equal-area projections (figs. 2, 3). The average magnitudes of these changes for the three loading cycles are shown in figure 4, and the orientations of principal strain axes are shown in figures 5 and 6 . The net principal strain magnitudes as a function of hydrostatic stress are presented in figure 7 . The calculations were made using the computer program described by Nichols, Abel, and Lee (1968). 
The results for the intervals between 700 and $900 \mathrm{psi}$ (pounds per square inch) hydrostatic pressure on the first loading cycle were so anomalous that a deformation ellipsoid could not be constructed.
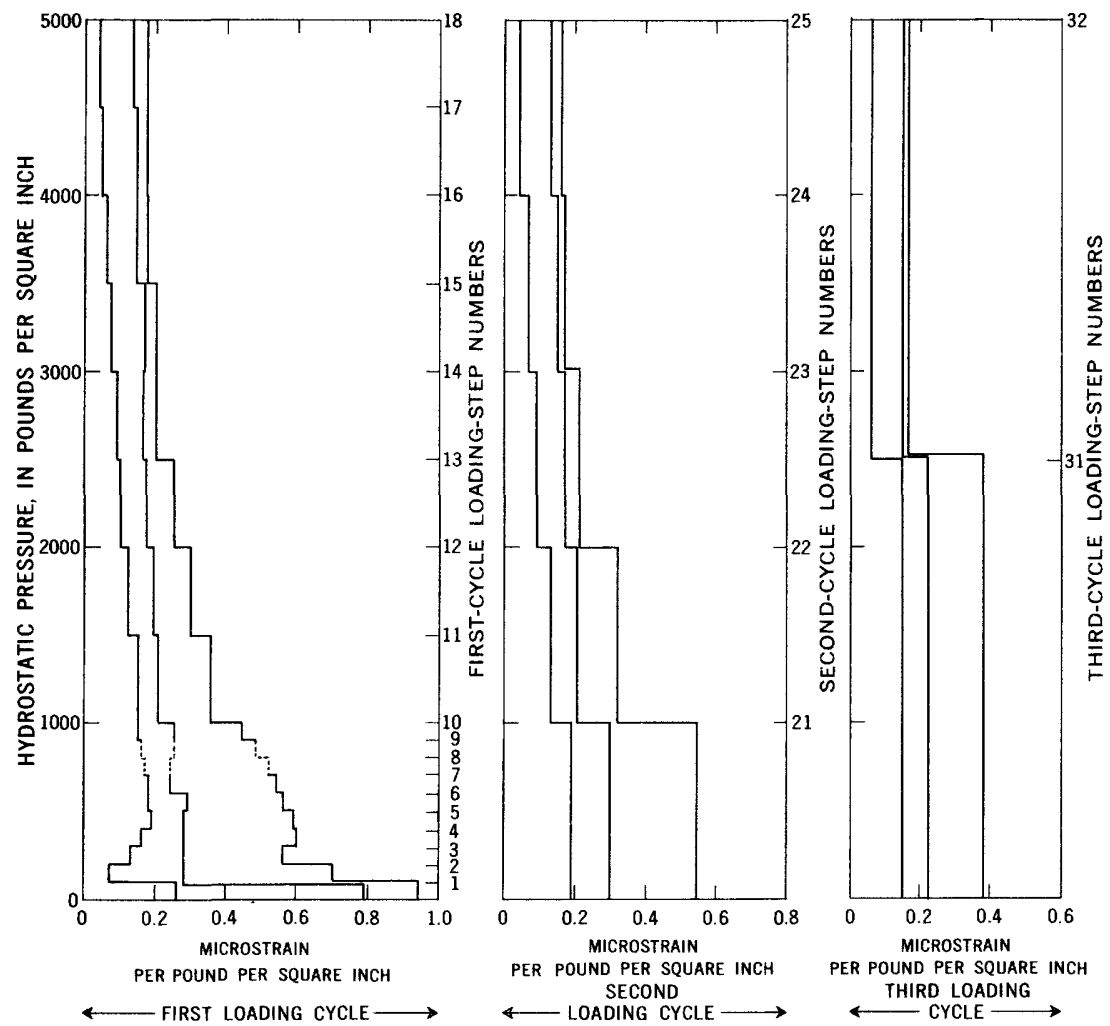

Figure 4. - Graphs showing microstrain per pound per square inch as a function of hydrostatic pressure.

The curves of magnitudes of principal strain changes and principal strains (figs. 4,7 ) were projected through the interval 700 to $900 \mathrm{psi}$. The curves for subsequent loading cycles suggest that no large errors in magnitude were introduced by using this procedure. During the 700- to 900-psi pressure interval, the trend of clockwise rotation of the $\varepsilon_{2}$ and $\varepsilon_{3}$ axes ceased. The attitude of $\varepsilon_{3}$ remained nearly fixed thereafter, and rotation of the $\varepsilon_{1}$ and $\varepsilon_{2}$ axes began. This behavior continued during the second and third loading cycles, perhaps as a result of permanent closure of one or more sets of microfractures favorably alined with the $\varepsilon_{3}$ direction. Factors not yet thoroughly evaluated are the effects of specimen geometry, the cumulative effects of creep in the sample and in 
the strain gage adhesive, and strain resulting from temperature changes as the rock was deformed.

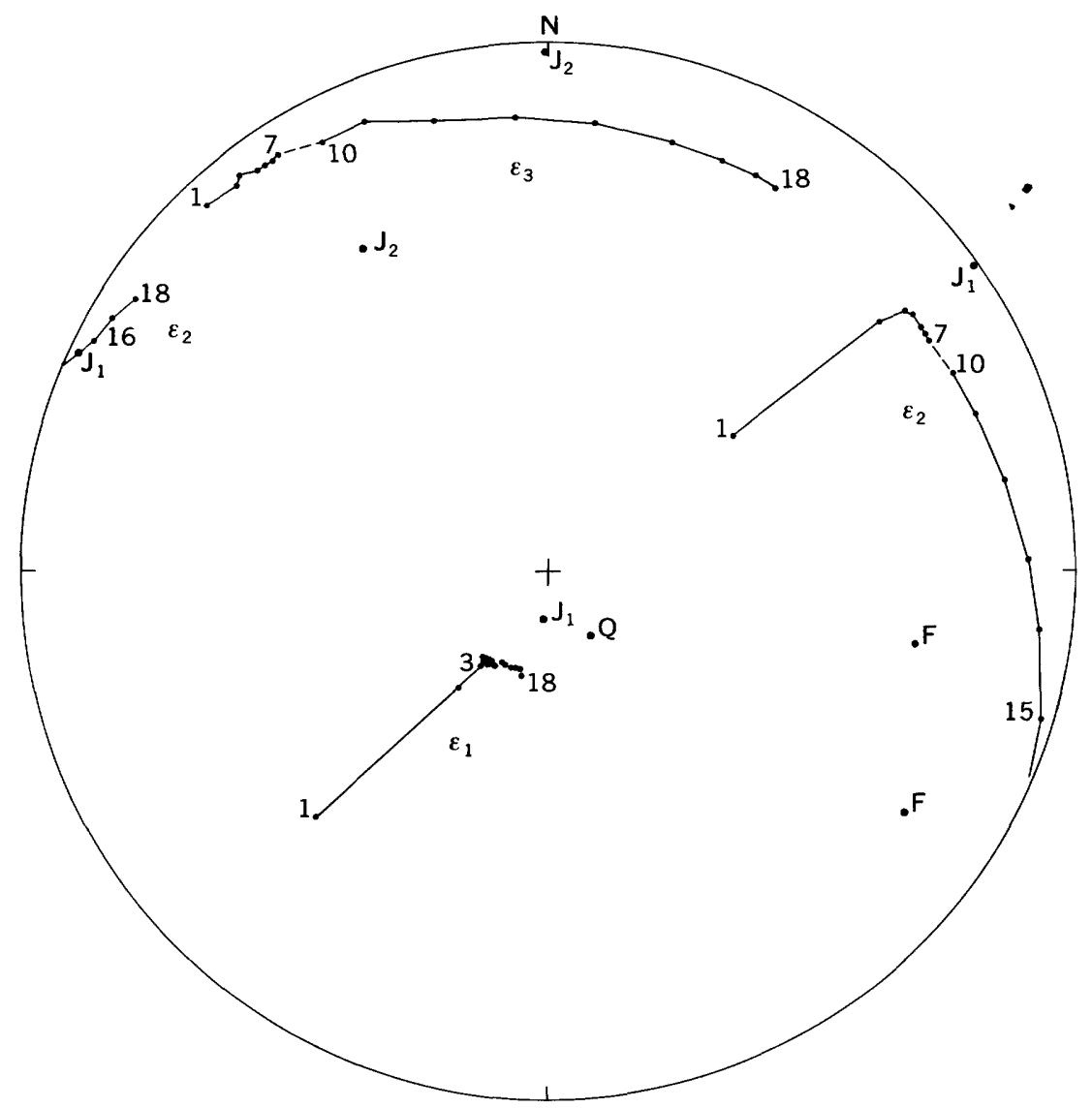

Figure 5. - Equal-area lower hemisphere projection of successive positions of the principal axes of the strain ellipsoid for the first loading cycle. $\varepsilon_{1}$, $\varepsilon_{2}$, and $\varepsilon_{3}$ are maximum, intermediate, and minimum compressive strains. Also shown are poles of foliation (F), quarry floor (Q), three sets of prominent joints $\left(J_{1}\right)$, and two sets of moderate joints $\left(J_{2}\right)$.

The directions of high modulus that I calculated agree very well with previously published values. The average direction of maximum modulus in the horizontal plane is $\mathrm{N} .51^{\circ} \mathrm{E}$. over a stress range from 0 to approximately 4,000 psi for specimens from the Mount Airy quarry, as determined by Hooker and Johnson (1969, p. 14). The solution of the directions is based on the assumption that one of the principal modulus directions is vertical and that the other two lie in the horizontal plane. The information in the 
present report shows that the direction of greatest strain, corresponding to the direction of minimum modulus, is nearly vertical for pressures up to about $3,000 \mathrm{psi}$. It is recognized that the two remaining principal modulus directions are forced to be horizontal by an ellipsoidal solution. Nonetheless, the average attitude of minimum strain is $\mathrm{N} .42^{\circ} \mathrm{E} ., 10^{\circ} \mathrm{NE}$; and that of intermediate strain varies from $\mathrm{N}$. $50^{\circ} \mathrm{W}$. to $\mathrm{N}$. $80^{\circ} \mathrm{W}$., with the plunge increasing from nearly horizontal to nearly vertical as pressure increases.

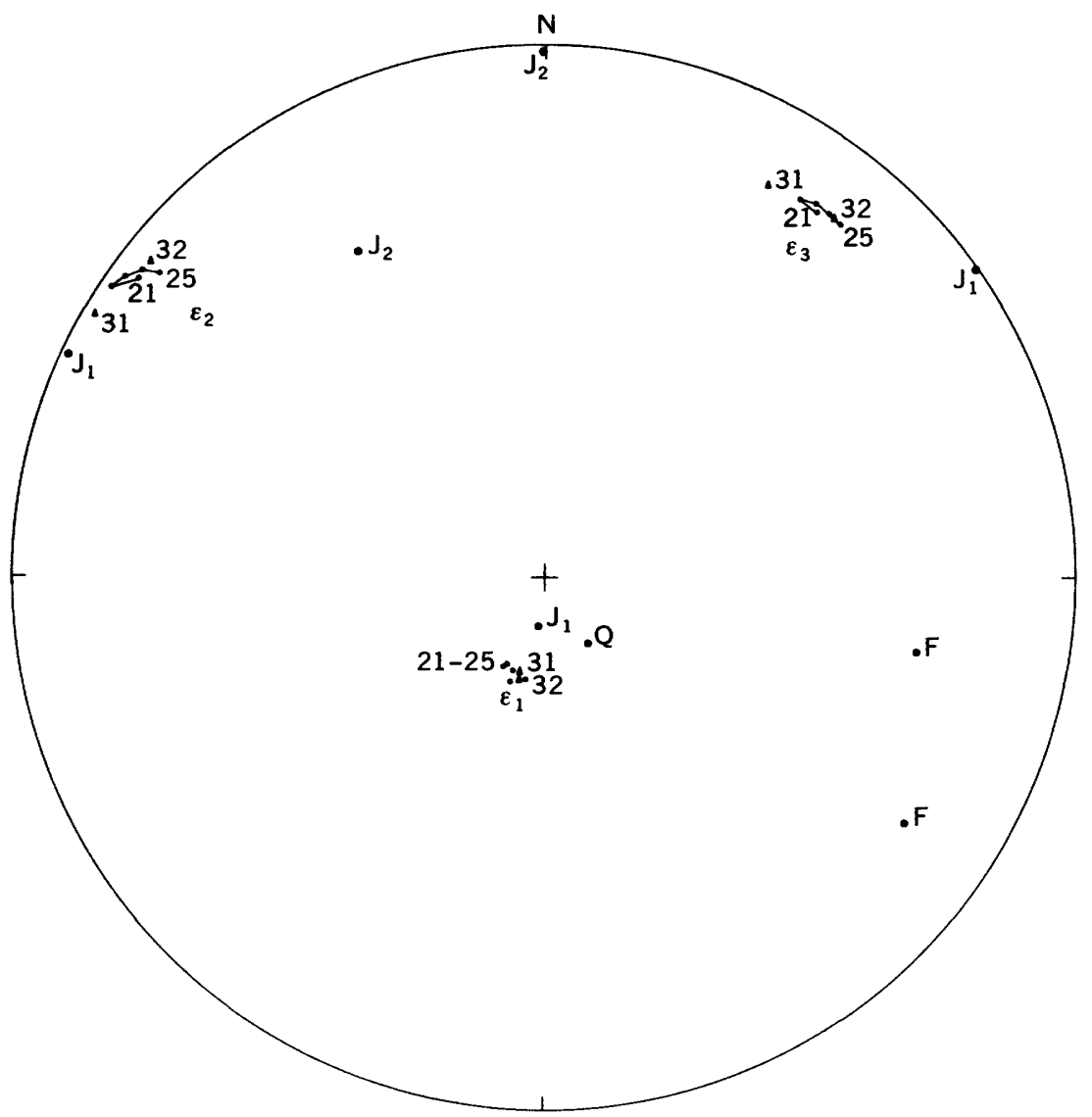

Figure 6. - Equal-area lower hemisphere projection of successive positions of the principal axes of the strain ellipsoid for the second and third loading cycles. $\varepsilon_{1}, \varepsilon_{2}$, and $\varepsilon_{3}$ are maximum, intermediate, and minimum compressive strains. Loading-step numbers 21-25 (dots) are for second loading cycle; loading-step numbers 31 and 32 (triangles) are for the third. Also shown are poles of foliation (F), quarry floor (Q), three sets of prominent joints $\left(J_{1}\right)$, and two sets of moderate joints $\left(J_{2}\right)$. 


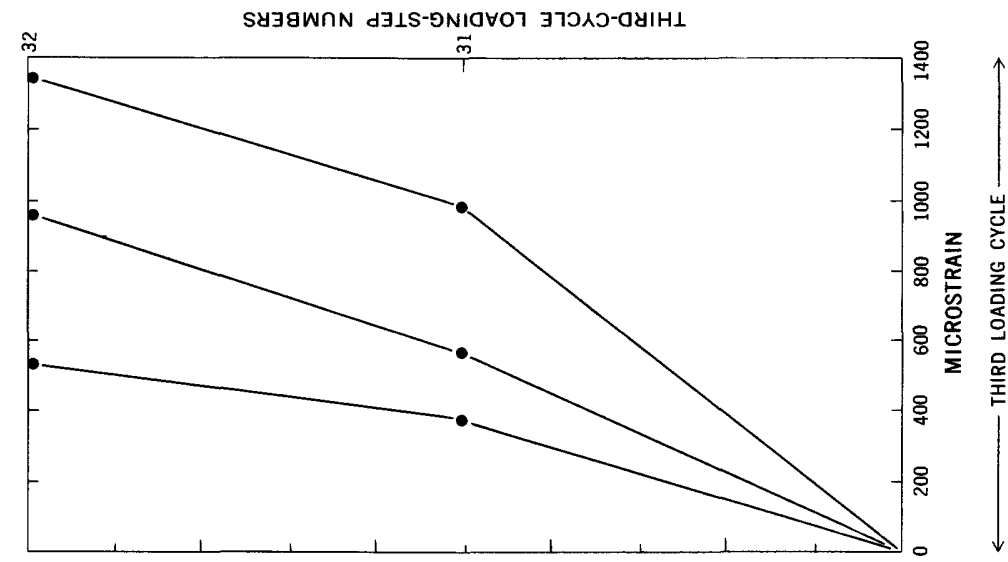

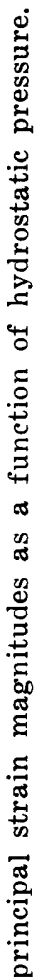

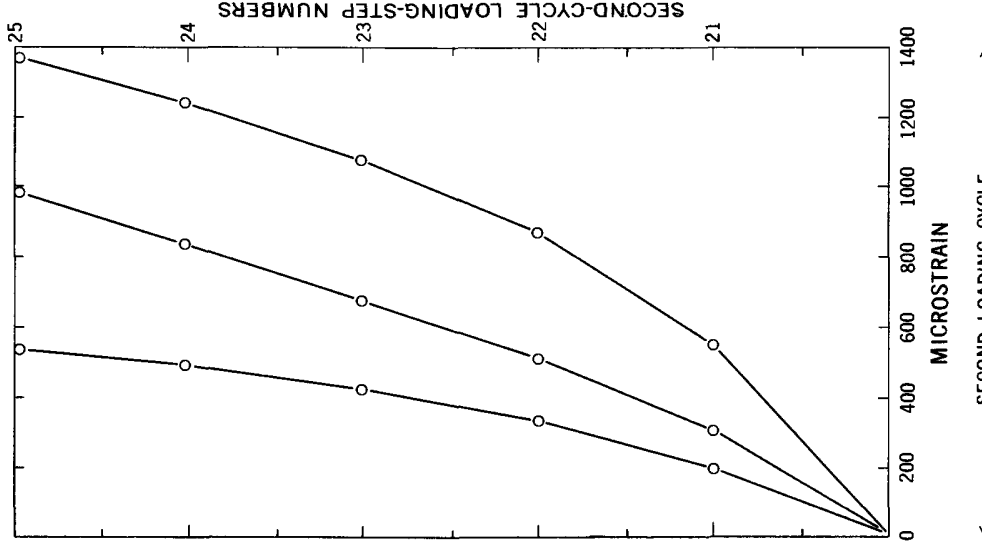

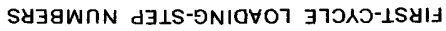

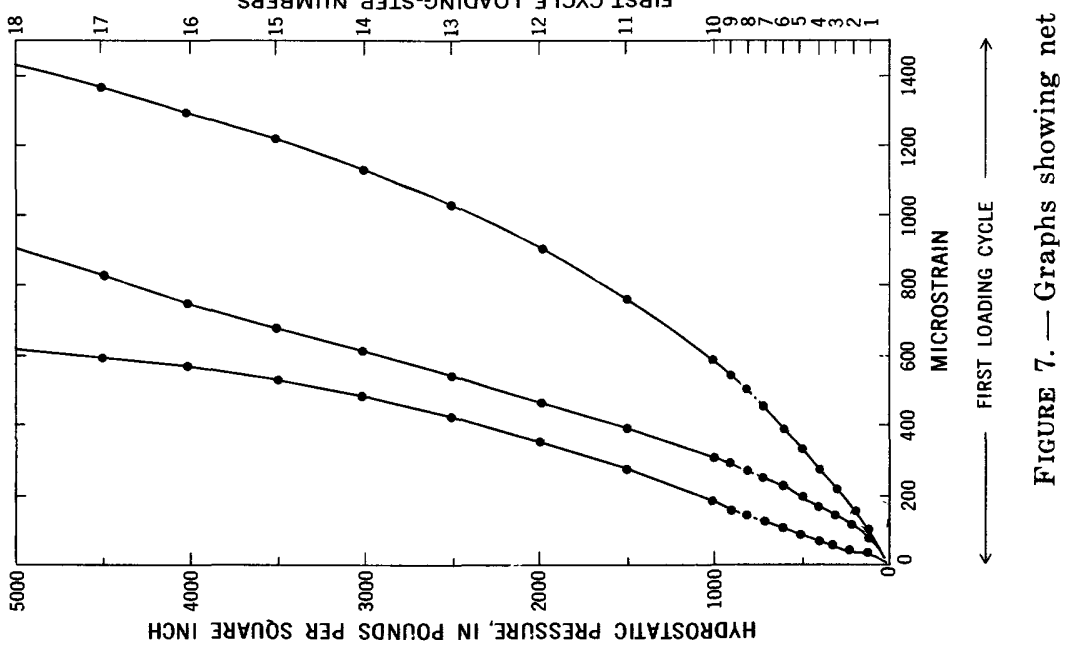


Directions of deformation axes appear to be related to attitudes of geologic features mapped in the quarry by F. T. Lee (unpub. data, 1970). The specimen tested for the present report was taken from a site in the quarry where an indistinct foliation trends N. $35^{\circ}$ E. and dips $70^{\circ} \mathrm{NW}$. and where three sets of joints, somewhat enlarged and emphasized by blasting, occur. The attitudes of these joints are N. $25^{\circ}$ E., vertical; N. $80^{\circ}$ W., $8^{\circ}$ NE. (a sheeting joint) ; and east-west, vertical. Lee described the first two as major (prominent) and the third as intermediate (moderate). At a nearby site, about 125 feet northeast of the overcoring location, the foliation strikes $\mathrm{N} .12^{\circ} \mathrm{E}$. and dips $60^{\circ} \mathrm{NW}$. At this site a prominent joint strikes $\mathrm{N} .35^{\circ} \mathrm{W}$. and is vertical. A moderate joint strikes $\mathrm{N} .60^{\circ} \mathrm{E}$. and dips $60^{\circ} \mathrm{SE}$. The quarry floor at the sampling site slopes N. $30^{\circ} \mathrm{W}$. at about $12^{\circ}$. These data are plotted on the equal-area diagrams (figs. $2,3,5,6$ ). Under hydrostatic loading, maximum deformation of the specimen should occur in the direction normal to planes parallel to open fractures. In order to examine the relationship between the poles (normals) of the planes of joints and foliation and the principal strain axes, the poles and axes are plotted together. After the first-cycle instability, previously noted, the direction of least strain change, $\Delta \varepsilon_{3}$, remains fairly constant for all pressures. The axes $\Delta \varepsilon_{1}$ and $\Delta \varepsilon_{2}$ rotate counterclockwise as pressure increases; however, they remain roughly in the plane which contains poles of two prominent joints, one moderate joint, the quarry floor, and the foliation. Poles of two moderate joints lie in the direction of greatest modulus and at $\mathrm{N}$ (horizontal). Possibly, microfractures parallel to the moderate joints closed permanently during the first loading cycle. The nonlinear stress-strain curves (fig. 7) show that the rock stiffens under increasing load, thus tending to support the assumed presence of microfractures.

\section{CONCLUSIONS}

The directional deformation characteristics of rocks can be determined from single rock specimens that are properly strain gaged and subjected to hydrostatic pressure. The immediate value of the method is to permit more precise stress calculations from strain measurements, such as those obtained with the solid-inclusion borehole probe of Nichols, Abel, and Lee (1968). Knowledge of the direction and magnitude variation of the deformation anisotropy of the host rock will remove the necessity of simplifying, perhaps erroneously, assumptions of isotropic elastic properties of the host rock. Additionally, this knowledge may permit the deciphering of a record of discrete episodes of tectonic loading which have impressed permanent changes on the rock fabric. 


\section{REFERENCES CITED}

Becker, R. M., 1968, An anisotropic elastic solution for testing stress relief cores: U.S. Bur. Mines Rept. Inv. 7143, 15 p.

Becker, R. M., and Hooker, V. E., 1967, Some anisotropic considerations in rock stress determinations: U.S. Bur. Mines Rept. Inv. 6965, 23 p.

Dietrich, R. V., 1961, Petrology of the Mount Airy "granite": Virginia Polytech. Inst. Bull., Eng. Expt. Sta. Ser. 144, v. 54, no. 6, 63 p.

Douglass, P. M., and Voight, B., 1969, Anisotropy of granites-a reflection of microscopic fabric: Geotechnique, v. 19, no. 3, p. 376-398.

Friedman, Melvin, 1967, Measurement of the state of residual elastic strain in quartzose rocks by means of X-ray diffractometry: Norelco Reporter, v. 14, p. $7-9,35$.

Hooker, V. E., and Johnson, C. F., 1969, Near-surface horizontal stresses including the effects of rock anisotropy: U.S. Bur. Mines Rept. Inv. 7224, $29 \mathrm{p}$.

Leeman, E. R., 1964, Borehole rock stress measuring instruments, pt. 2 of The measurement of stress in rock: South African Inst. Mining and Metall. Jour., v. 65, p. 82-114.

Merrill, R. H., and Peterson, J. R., 1961, Deformation of a borehole in rock: U.S. Bur. Mines Rept. Inv. 5881, 32 p.

Nichols, T. C., Jr., Abel, J. F., Jr., and Lee, F. T., 1968, A solid-inclusion borehole probe to determine three-dimensional stress changes at a point in a rock mass: U.S. Geol. Survey Bull. 1258-C, 28 p.

Norman, C. E., 1967, Microfractures in brittle rocks-their relationship to larger scale structural features and existing ground stresses: Ohio State Univ. Ph. D. dissert., 169 p.

Obert, Leonard, and Duvall, W. I., 1967, Rock mechanics and the design of structures in rock: New York, John Wiley \& Sons, Inc., 650 p.

Panek, L. A., 1966, Calculation of the average ground stress components from measurements of the diametral deformation of a drill hole: U.S. Bur. Mines Rept. Inv. 6732, 41 p.

Ramsay, J. G., 1967, Folding and fracturing of rocks: New York, McGrawHill Book Co., 568 p.

Stuckey, J. L., and Conrad, S. G., 1958, Explanatory text for geologic map of North Carolina: North Carolina Dept. Conserv. and Devel., Mineral Resources Bull. 71, p. 22-23.

Timoshenko, S., and Goodier, J. N., 1951, Theory of elasticity [2d ed.]: New York, McGraw-Hill Book Co., 506 p. 


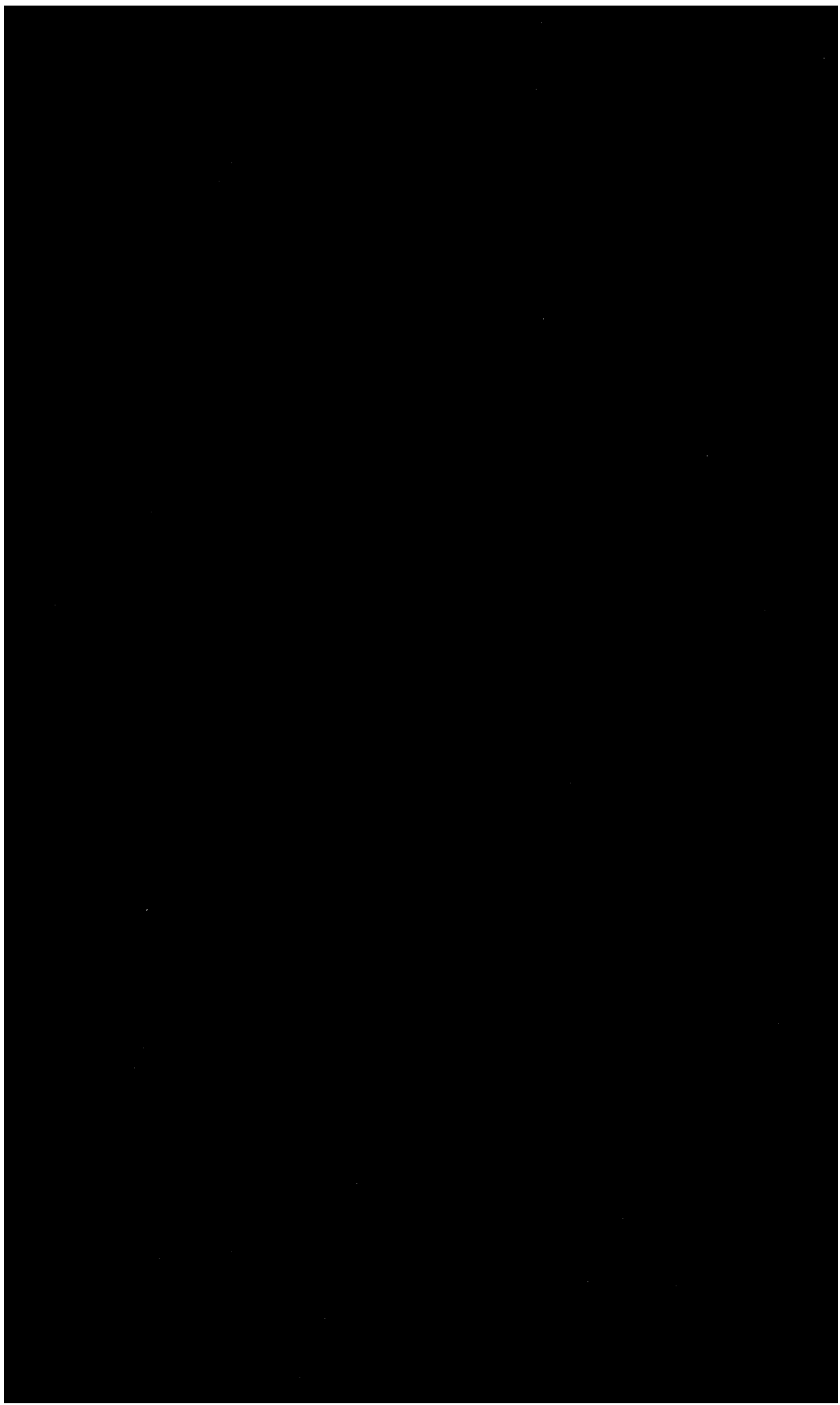




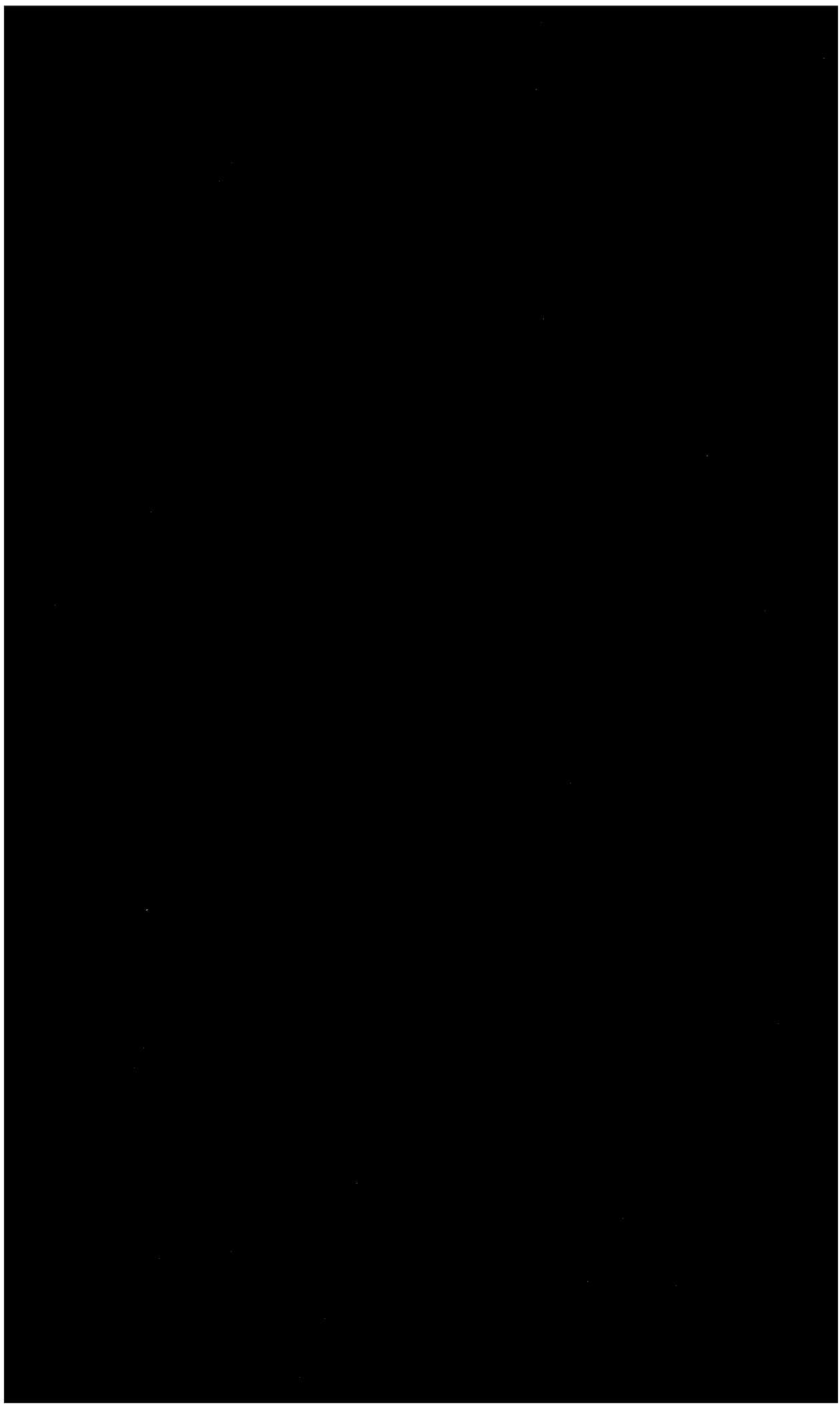

